An elegant method to estimate helium-like ion densities from visible and VUV plasma spectroscopy

This content has been downloaded from IOPscience. Please scroll down to see the full text. 1993 Plasma Phys. Control. Fusion 351553

(http://iopscience.iop.org/0741-3335/35/11/005)

View the table of contents for this issue, or go to the journal homepage for more

Download details:

IP Address: 130.237.34.28

This content was downloaded on 16/11/2015 at 09:27

Please note that terms and conditions apply. 


\title{
An elegant method to estimate helium-like ion densities from visible and VUV plasma spectroscopy
}

\author{
K-D Zastrow†, J H Brzozowskiț, P Hörling† and E Rachlew-Käline† \\ $\dagger$ Department of Physics I, The AIfvén Laboratory, Royal Institute of Technology, S-10044 \\ Stockholm, Sweden \\ $¥$ Department of Fusion Plasma Physics, The Alfvén Laboratory, Royal Institute of \\ Technology, S-10044 Stockholm, Sweden
}

Received 29 January 1993, in final form 14 May 1993

\begin{abstract}
A method is presented to estimate the densities of He-like carbon and oxygen ions from the observation of the Li-like $3 p \rightarrow 3 s$ transitions in the visible and the $3 p \rightarrow 2$ s transitions in the vacuum ultraviolet. The method is based on a zero-dimensional model for plasmas with short particle confinement times. General coefficients for this study are derived and evaluated numerically. The method is applied to Extrap- $T 1$ reversed field pinch data.
\end{abstract}

\section{Introduction}

A standard task of plasma spectroscopy is to determine absolute concentrations of impurities. Already at modest temperature, around $100 \mathrm{eV}$, this requires instrumentation over a wide wavelength range. Resonance lines for ionization stages of light impurities up to Li-like ones are in the vacuum ultraviolet (VUV) wavelength region, and for He-like and H-like species they are in the soft X-ray region. Visible spectroscopy, on the other hand, is easy to calibrate and can be performed in air. The light can be transported by optical fibres from the experiment to the spectroscopic equipment.

As long as species up to Li-like ones are studied, visible and VUV lines can be found to characterize the ions. In this paper we present a simple method, applicable to plasmas with large particle fluxes and short confinement times, that can be used to estimate He-like ion densities from a zero-dimensional model. This model should be applicable in particular to small and medium size reversed field pinch (RFP) experiments (Bodin 1990).

It can be shown that transport processes under the constraint of ambipolarity are characterized by mass and charge independent diffusion coefficients (Fussmann et al 1991). If we assume that the particle confinement time as a result of these transport processes is the same for all ion species, the particle confinement time can be obtained from the intensity of $\mathrm{H} \alpha$ (Johnson and Hinnov 1973).

The method and the conditions under which it may be used are outlined in section 2 . In section 3 general results for carbon and oxygen are presented. Finally, the method is applied to Extrap-T1 RFP discharges.

\section{Method}

In a zero-dimensional model, the time development of the He-like ion density can be written as 


$$
\begin{aligned}
\frac{\mathrm{d} n_{\mathrm{He}}}{\mathrm{d} t}=-\frac{n_{\mathrm{He}}}{\tau_{\mathrm{p}}} & +n_{\mathrm{Li}} n_{\mathrm{e}} S_{\mathrm{Li} \rightarrow \mathrm{He}}\left(T_{\mathrm{e}}, n_{\mathrm{e}}\right)-n_{\mathrm{He}} n_{\mathrm{e}} S_{\mathrm{He} \rightarrow \mathrm{H}}\left(T_{\mathrm{e}}, n_{\mathrm{e}}\right)-n_{\mathrm{He}} n_{\mathrm{e}} \alpha_{\mathrm{He} \rightarrow \mathrm{Li}}\left(T_{\mathrm{e}}, n_{\mathrm{e}}\right) \\
& +n_{H} n_{\mathrm{e}} \alpha_{\mathrm{H} \rightarrow \mathrm{He}}\left(T_{\mathrm{e}}, n_{\mathrm{e}}\right) .
\end{aligned}
$$

Here, $n_{\mathrm{e}}, n_{\mathrm{Lj}}, n_{\mathrm{He}}$, and $n_{\mathrm{H}}$ are the number densities of electrons, and of Li-, He- and $\mathrm{H}$-like ions of the studied species, $\tau_{\mathrm{p}}$ is the particle confinement time and $S\left(T_{\mathrm{e}}, n_{\mathrm{e}}\right)$ and $\alpha\left(T_{\mathrm{e}}, n_{\mathrm{e}}\right)$ are the collisional dielectronic rate coefficients for ionization and recombination (Summers 1974) as a function of electron temperature, $T_{\mathrm{e}}$, and electron density, $n_{\mathrm{e}}$.

The ionization potential for He-like ions is much higher than for Li-like ions. Therefore, in general, $S_{\mathrm{He} \rightarrow \mathrm{H}}\left(T_{\mathrm{e}}, n_{\mathrm{e}}\right) \ll S_{\mathrm{Li} \rightarrow \mathrm{He}}\left(T_{\mathrm{e}}, n_{\mathrm{e}}\right)$. Also at sufficiently high temperatures $\alpha_{\mathrm{He} \rightarrow \mathrm{Li}}\left(T_{\mathrm{e}}, n_{\mathrm{e}}\right) \ll S_{\mathrm{Li} \rightarrow \mathrm{He}}\left(T_{\mathrm{e}}, n_{\mathrm{e}}\right)$. Thus, we may simplify equation (1) to

$$
\frac{\mathrm{d} n_{\mathrm{He}}}{\mathrm{d} t} \approx-\frac{n_{\mathrm{He}}}{\tau_{\mathrm{p}}}+n_{\mathrm{Li}} n_{\mathrm{e}} S_{\mathrm{Li} \rightarrow \mathrm{He}}\left(T_{\mathrm{e}}, n_{\mathrm{e}}\right) .
$$

A similar simplification cannot be made for other ionization stages of carbon and oxygen, since the ionization potential for adjacent ionization stages is normally comparable. It is only because of the closed-shell properties of He-like ions that equation (2) can be used.

From equation (2), we obtain in equilibrium

$$
\frac{n_{\mathrm{He}}}{n_{\mathrm{Li}}}=\tau_{\mathrm{p}} n_{\mathrm{e}} S_{\mathrm{Li} \rightarrow \mathrm{He}}\left(T_{\mathrm{e}}, n_{\mathrm{e}}\right)
$$

which should be compared to the well known result that follows from a balance between ionization and recombination

$$
\frac{n_{\mathrm{He}}}{n_{\mathrm{Li}}}=\frac{S_{\mathrm{Li} \rightarrow \mathrm{He}}\left(T_{\mathrm{e}}, n_{\mathrm{e}}\right)}{\alpha_{\mathrm{He} \rightarrow \mathrm{Li}}\left(T_{\mathrm{e}}, n_{\mathrm{e}}\right)}
$$

As a result, the ratio between the fractional abundances of He-like and $\mathrm{Li}$-like ions is reduced by a factor $\tau_{\mathrm{p}} n_{\mathrm{e}} \alpha_{\mathrm{He} \rightarrow \mathrm{Li}}\left(T_{\mathrm{e}}, n_{\mathrm{e}}\right)$. The equilibrium charge state distribution is not reached due to the transient ionization (Carolan and Piotrowicz 1983).

In figures 1 and 2 the characteristic times for further ionization, $1 /\left(n_{\mathrm{e}} S_{\mathrm{He} \rightarrow \mathrm{H}}\right)$, and for recombination, $1 /\left(n_{\mathrm{e}} \alpha_{\mathrm{He} \rightarrow \mathrm{Li}}\right)$, are plotted. The rate coefficients were taken from Arnaud and Rothenflug (1985) corrected for multistep processes using the results of Summers (1974). For given density and temperature we can determine the largest particle confinement time that justifies the simplification made in equation (2) using these figures. A particle confinement time comparable with $1 /\left(n_{\mathrm{e}} S_{\mathrm{He} \rightarrow \mathrm{H}}\right)$ may still be acceptable. In this case, we shall obtain the sum of He-like and H-like ion densities from this analysis.

In order to estimate the abundance of He-like ions from equation (3) we have to know $n_{\mathrm{e}}, T_{\mathrm{e}}, n_{\mathrm{Li}}$ and $\tau_{\mathrm{p}}$. If we assume that the particle confinement time is the same for all plasma species, the particle confinement time can be obtained from the intensity of $\mathrm{H} \alpha$ (Johnson and Hinnov 1973) according to

$$
\tau_{\mathrm{p}}=\frac{\int n_{\mathrm{p}} \mathrm{d} V}{\int \Gamma_{\mathrm{H}} \mathrm{d} \sigma} \approx \frac{n_{\mathrm{p}} V}{\Gamma_{\mathrm{H}} A} .
$$

Here $n_{\mathrm{p}}$ is the number density of protons, $V$ is the total plasma volume and $A$ the total plasma surface. The flux of hydrogen atoms, $\Gamma_{\mathrm{H}}$, per unit area and time can be measured by observation of $\mathrm{H} \alpha$ (in photon $\mathrm{cm}^{-2} \mathrm{sr}^{-1} \mathrm{~s}^{-1}$ )

$$
\Gamma_{\mathrm{H}}=4 \pi(S / X)_{\mathrm{H}} l_{\mathrm{H} \alpha}
$$



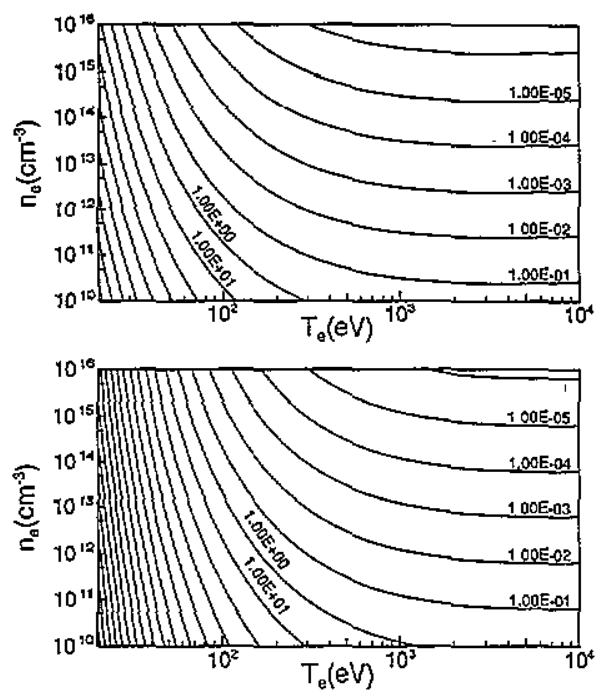

Figure 1. Contours of the characteristic time for further ionization, $1 /\left(n_{\mathrm{e}} S_{\mathrm{He} \rightarrow \mathrm{H}}\right)$, for carbon (top) and oxygen (bottom) in seconds.
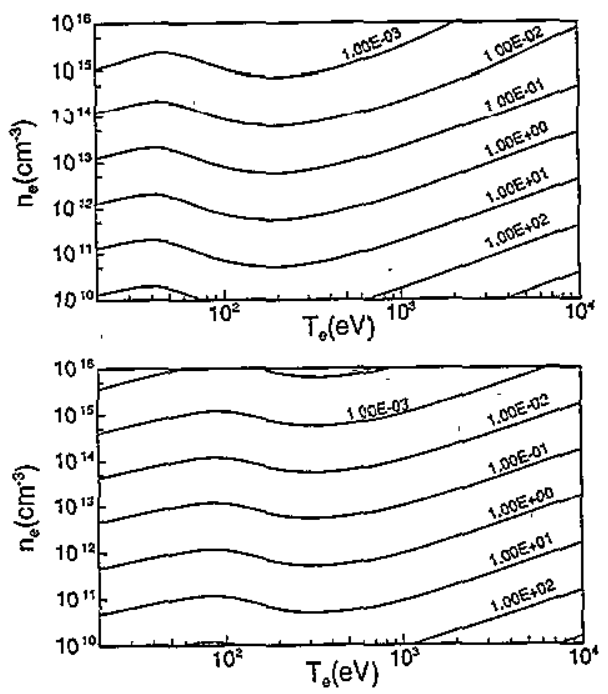

Figure 2. Contours of the characteristic time for

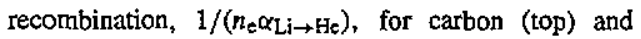
oxygen (bottom) in seconds.

Here $(S / X)_{\mathrm{H}}$ is the dimensionless number of ionizations per photon and $I_{\mathrm{H} \alpha}$ is the radiance of $H \alpha$.

The abundance of Li-like ions may be obtained from visible spectra, namely from the observation of $3 \mathrm{p}^{2} \mathrm{p}^{\mathrm{o}} \rightarrow 3 \mathrm{~s}^{2} \mathrm{~S}$ transitions, or from $3 \mathrm{p}^{2} \mathrm{P}^{\circ} \rightarrow 2 \mathrm{~s}^{2} \mathrm{~S}$ lines in the VUV wavelength region.

$$
n_{\mathrm{Li}}=\frac{l_{\mathrm{Li}}}{\left\langle n_{\mathrm{e}} \epsilon_{\mathrm{Li}}\right\rangle} \approx \frac{I_{\mathrm{Li}}}{(\ell / 4 \pi)\left\langle n_{\mathrm{e}}\right\rangle \epsilon_{\mathrm{Li}}\left(T_{\mathrm{e}}, n_{\mathrm{e}}\right\rangle} .
$$

Here $I_{\mathrm{Li}}$ is the measured radiance of the Li-like multiplet, $\epsilon_{\mathrm{Li}}\left(T_{\mathrm{e}}, n_{\mathrm{e}}\right)$ is the rate coefficient for the effective emissivity in photon $\mathrm{cm}^{3} \mathrm{~s}^{-1}$ of the Li-like multiplet accounting for multistep processes and () represents a line-of-sight average over the plasma column length $\ell$.

If we combine equations (3), (5), (6) and (7), assuming $n_{\mathrm{p}}=n_{\mathrm{e}}$ for simplicity, we find that the fraction of He-like ions, $f_{\mathrm{He}}=n_{\mathrm{He}} / n_{\mathrm{e}}$, is independent of the electron density, $n_{\mathrm{e}}$ :

$$
f_{\mathrm{He}}=\frac{V}{A \ell} \frac{I_{\mathrm{L} 1}}{I_{\mathrm{H} \alpha}} \frac{\left(S_{L i \rightarrow H e} / \epsilon_{\mathrm{Li}}\right)}{(S / X)_{\mathrm{H}}} .
$$

The reason for this is that, as $1 / \tau_{\mathrm{p}} \gg n_{\mathrm{e}} \alpha_{\mathrm{He} \rightarrow \mathrm{Li}}$, the Li-like ions are, in fact, in a state of influx, and so the concept of ionization per photon, which has already been applied succesfully to $\mathrm{C}^{1+}, \mathrm{C}^{2+}, \mathrm{O}^{1+}$ and $\mathrm{O}^{2+}$ ions (Behringer et al 1989) is extended to Li-like ions. It should be noted that the flux in this context is the flux of Li-like ions by transport. The influx at the plasma boundary is larger, and ions are lost at all previous ionization stages with a rate $\simeq 1 / \tau_{p}$.

The advantage of this formal density independence is that the estimate is not sensitive to errors in the measurement of $n_{\mathrm{e}}$, which otherwise result in error propagation. However, the dependence on $n_{\mathrm{e}}$ re-enters into equation (8) through the density dependence of the rate coefficients. 


\section{Theoretical results}

A more realistic approach to the estimate of He-like abundances will have to consider the spatial distribution of $n_{\mathrm{e}}$ and $T_{\mathrm{e}}$, the actual ratio $n_{\mathrm{p}} / n_{\mathrm{e}}$ as well as the proper gcometry of the line-of-sight. For this study, the quantity $S / \epsilon_{\mathrm{Li}}$ is needed separately, which is given in table 1 for carbon and in table 2 for oxygen for the visible transitions $3 \mathrm{p}^{2} \mathrm{P}^{0} \rightarrow 3 \mathrm{~s}^{2} \mathrm{~S}$. The corresponding quantities for the VUV transitions $3 \mathrm{p}^{2} \mathrm{P}^{\circ} \rightarrow 2 \mathrm{~s}^{2} \mathrm{~S}$ can be obtained by multiplication with the branching ratio (Klose and Wiese 1989). The result for the visible transitions is also displayed in figure 3. The excitation rate coefficients for oxygen have been calculated from the cross section results of Zhang et al (1990). The data for carbon have been taken from Cochrane and McWhirter (1983). Since the $3 \mathrm{p}^{2} \mathrm{P}^{\circ}$ level is close to the ionization threshold, redistribution processes affect the effective excitation to $3 \mathrm{p}^{2} \mathrm{P}^{\circ}$ and the ionization so that the density dependence of $\epsilon_{\mathrm{Li}}$ and $S$ are comparable. Thus, the coefficient $S / \epsilon_{\mathrm{Li}}$ is fairly independent of density.

Table 1. Number of ionizations per photon $S_{\mathrm{Li} \rightarrow \mathrm{He}} / \epsilon_{\mathrm{Li}}$ for carbon for the transition $3 \mathrm{p}^{2} \mathrm{P}^{\mathrm{o}} \rightarrow$ $3 \mathrm{~s}^{2} \mathrm{~S}(5801.3-5812.0 \AA)$. The corresponding quantities for the transition $3 \mathrm{p}^{2} \mathrm{p}^{\mathrm{o}} \rightarrow 2 \mathrm{~s}^{2} \mathrm{~S}$ (312.42-312.46 $\AA$ ) can be obtained by multiplication with the branching ratio $0.317 / 44.9$ (Klose and Wiese 1989).

\begin{tabular}{lllll}
\hline & \multicolumn{4}{c}{$n_{\mathrm{e}}\left(\mathrm{cm}^{-3}\right)$} \\
\cline { 2 - 5 }$T_{\mathrm{e}}(\mathrm{eV})$ & $\leqslant 10^{13}$ & $10^{14}$ & $10^{15}$ & $10^{16}$ \\
\hline $1.0 \mathrm{E}+01$ & $6.19 \mathrm{E}+00$ & $8.36 \mathrm{E}+00$ & $1.18 \mathrm{E}+01$ & $1.40 \mathrm{E}+01$ \\
$2.0 \mathrm{E}+01$ & $3.23 \mathrm{E}+01$ & $3.90 \mathrm{E}+01$ & $4.77 \mathrm{E}+01$ & $4.72 \mathrm{E}+01$ \\
$3.0 \mathrm{E}+01$ & $6.05 \mathrm{E}+01$ & $6.95 \mathrm{E}+01$ & $8.09 \mathrm{E}+01$ & $7.58 \mathrm{E}+01$ \\
$5.0 \mathrm{E}+01$ & $1.04 \mathrm{E}+02$ & $1.15 \mathrm{E}+02$ & $1.29 \mathrm{E}+02$ & $1.18 \mathrm{E}+02$ \\
$7.0 \mathrm{E}+01$ & $1.35 \mathrm{E}+02$ & $1.46 \mathrm{E}+02$ & $1.61 \mathrm{E}+02$ & $1.48 \mathrm{E}+02$ \\
$1.0 \mathrm{E}+02$ & $1.67 \mathrm{E}+02$ & $1.78 \mathrm{E}+02$ & $1.94 \mathrm{E}+02$ & $1.81 \mathrm{E}+02$ \\
$2.0 \mathrm{E}+02$ & $2.14 \mathrm{E}+02$ & $2.24 \mathrm{E}+02$ & $2.43 \mathrm{E}+02$ & $2.39 \mathrm{E}+02$ \\
$3.0 \mathrm{E}+02$ & $2.42 \mathrm{E}+02$ & $2.51 \mathrm{E}+02$ & $2.71 \mathrm{E}+02$ & $2.74 \mathrm{E}+02$ \\
$5.0 \mathrm{E}+02$ & $2.75 \mathrm{E}+02$ & $2.84 \mathrm{E}+02$ & $3.06 \mathrm{E}+02$ & $3.19 \mathrm{E}+02$ \\
$7.0 \mathrm{E}+02$ & $2.95 \mathrm{E}+02$ & $3.03 \mathrm{E}+02$ & $3.25 \mathrm{E}+02$ & $3.45 \mathrm{E}+02$ \\
$1.0 \mathrm{E}+03$ & $3.14 \mathrm{E}+02$ & $3.21 \mathrm{E}+02$ & $3.42 \mathrm{E}+02$ & $3.68 \mathrm{E}+02$ \\
$2.0 \mathrm{E}+03$ & $3.39 \mathrm{E}+02$ & $3.44 \mathrm{E}+02$ & $3.63 \mathrm{E}+02$ & $4.00 \mathrm{E}+02$ \\
$3.0 \mathrm{E}+03$ & $3.48 \mathrm{E}+02$ & $3.51 \mathrm{E}+02$ & $3.68 \mathrm{E}+02$ & $4.11 \mathrm{E}+02$ \\
$5.0 \mathrm{E}+03$ & $3.55 \mathrm{E}+02$ & $3.56 \mathrm{E}+02$ & $3.71 \mathrm{E}+02$ & $4.19 \mathrm{E}+02$ \\
$7.0 \mathrm{E}+03$ & $3.56 \mathrm{E}+02$ & $3.56 \mathrm{E}+02$ & $3.70 \mathrm{E}+02$ & $4.19 \mathrm{E}+02$ \\
$1.0 \mathrm{E}+04$ & $3.57 \mathrm{E}+02$ & $3.56 \mathrm{E}+02$ & $3.68 \mathrm{E}+02$ & $4.18 \mathrm{E}+02$ \\
$2.0 \mathrm{E}+04$ & $3.55 \mathrm{E}+02$ & $3.51 \mathrm{E}+02$ & $3.60 \mathrm{E}+02$ & $4.09 \mathrm{E}+02$ \\
\hline
\end{tabular}

The coefficient $(S / X)_{\mathrm{H}}$ is available from Johnson and Hinnov (1973). For illustrative reasons and for simple estimates, we also present the ratio of the two quantities, as given in equation (8). As one can see in figure 4, this quantity depends on electron density. The dependence stems mainly from the well known but often neglected dependence of $(S / X)_{\mathrm{H}}$ on electron density.

\section{Application to Extrap-T1 RFP data}

We have applied our method to the estimate of He-like oxygen abundances in Extrap-T1 RFP discharges (Brunsell et al 1991) from the radiance of $\mathrm{O}^{5+} 3 \mathrm{p}^{2} \mathrm{P}^{0} \rightarrow 2 \mathrm{~s}^{2} \mathrm{~S}$ at $150.1 \AA$. 
Table 2. Number of ionizations per photon $S_{\mathrm{L}, \rightarrow \mathrm{He}} / \epsilon_{\mathrm{Li}}$ for oxygen for the transition $3 \mathrm{p}^{2} \mathrm{po} \rightarrow$ $3 \mathrm{~s}^{2} \mathrm{~S}(3811.4-3834.2)$. The corresponding quantities for the transition $3 \mathrm{p}^{2} \mathrm{po} \rightarrow 2 \mathrm{~s}^{2} \mathrm{~S}(150.09-$ $150.12 \AA$ ) can be obtained by multiplication with the branching ratio $0.510 / 254$ (Klose and Wiese 1989).

\begin{tabular}{lllll}
\hline & \multicolumn{4}{c}{$n_{\mathrm{e}}\left(\mathrm{cm}^{-3}\right)$} \\
\cline { 2 - 5 }$T_{\mathrm{e}}(\mathrm{eV})$ & $\leqslant 10^{13}$ & $10^{14}$ & $10^{15}$ & $10^{16}$ \\
\hline $1.0 \mathrm{E}+01$ & $8.72 \mathrm{E}-01$ & $9.61 \mathrm{E}-01$ & $1.07 \mathrm{E}+00$ & $1.04 \mathrm{E}+00$ \\
$2.0 \mathrm{E}+01$ & $2.00 \mathrm{E}+01$ & $2.16 \mathrm{E}+01$ & $2.39 \mathrm{E}+01$ & $2.25 \mathrm{E}+01$ \\
$3.0 \mathrm{E}+01$ & $6.19 \mathrm{E}+01$ & $6.56 \mathrm{E}+01$ & $7.17 \mathrm{E}+01$ & $6.71 \mathrm{E}+01$ \\
$5.0 \mathrm{E}+01$ & $1.60 \mathrm{E}+02$ & $1.67 \mathrm{E}+02$ & $1.80 \mathrm{E}+02$ & $1.71 \mathrm{E}+02$ \\
$7.0 \mathrm{E}+01$ & $2.45 \mathrm{E}+02$ & $2.53 \mathrm{E}+02$ & $2.72 \mathrm{E}+02$ & $2.66 \mathrm{E}+02$ \\
$1.0 \mathrm{E}+02$ & $3.43 \mathrm{E}+02$ & $3.53 \mathrm{E}+02$ & $3.77 \mathrm{E}+02$ & $3.81 \mathrm{E}+02$ \\
$2.0 \mathrm{E}+02$ & $5.46 \mathrm{E}+02$ & $5.57 \mathrm{E}+02$ & $5.90 \mathrm{E}+02$ & $6.33 \mathrm{E}+02$ \\
$3.0 \mathrm{E}+02$ & $6.64 \mathrm{E}+02$ & $6.75 \mathrm{E}+02$ & $7.12 \mathrm{E}+02$ & $7.84 \mathrm{E}+02$ \\
$5.0 \mathrm{E}+02$ & $7.98 \mathrm{E}+02$ & $8.09 \mathrm{E}+02$ & $8.49 \mathrm{E}+02$ & $9.61 \mathrm{E}+02$ \\
$7.0 \mathrm{E}+02$ & $8.80 \mathrm{E}+02$ & $8.91 \mathrm{E}+02$ & $9.32 \mathrm{E}+02$ & $1.07 \mathrm{E}+03$ \\
$1.0 \mathrm{E}+03$ & $9.70 \mathrm{E}+02$ & $9.82 \mathrm{E}+02$ & $1.02 \mathrm{E}+03$ & $1.18 \mathrm{E}+03$ \\
$2.0 \mathrm{E}+03$ & $1.10 \mathrm{E}+03$ & $1.12 \mathrm{E}+03$ & $1.15 \mathrm{E}+03$ & $1.32 \mathrm{E}+03$ \\
$3.0 \mathrm{E}+03$ & $1.16 \mathrm{E}+03$ & $1.17 \mathrm{E}+03$ & $1.20 \mathrm{E}+03$ & $1.37 \mathrm{E}+03$ \\
$5.0 \mathrm{E}+03$ & $1.22 \mathrm{E}+03$ & $1.23 \mathrm{E}+03$ & $1.25 \mathrm{E}+03$ & $1.41 \mathrm{E}+03$ \\
$7.0 \mathrm{E}+03$ & $1.26 \mathrm{E}+03$ & $1.26 \mathrm{E}+03$ & $1.28 \mathrm{E}+03$ & $1.43 \mathrm{E}+03$ \\
$1.0 \mathrm{E}+04$ & $1.27 \mathrm{E}+03$ & $1.28 \mathrm{E}+03$ & $1.29 \mathrm{E}+03$ & $1.42 \mathrm{E}+03$ \\
$2.0 \mathrm{E}+04$ & $1.30 \mathrm{E}+03$ & $1.31 \mathrm{E}+03$ & $1.30 \mathrm{E}+03$ & $1.41 \mathrm{E}+03$ \\
\hline
\end{tabular}
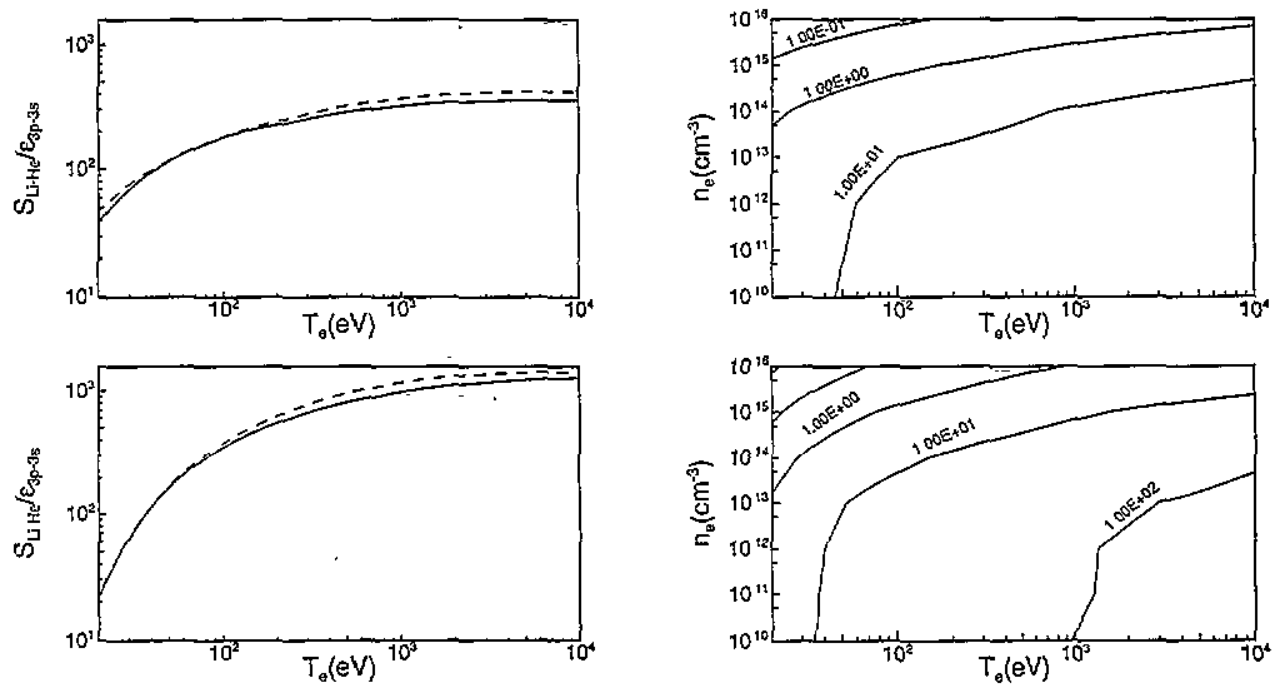

Figure 3. Number of ionizations per photon $S_{\mathrm{Li} \rightarrow \mathrm{He}} / \epsilon_{\mathrm{Li}}$ for carbon (top, see table 1) and oxygen (bottom, see table 2) for the transition $3 \mathrm{p}^{2} \mathrm{p}^{\circ} \rightarrow 3 \mathrm{~s}^{2} \mathrm{~S}$. The full curve is for $n_{\mathrm{e}}=1.0 \times 10^{14} \mathrm{~cm}^{-3}$ and the broken curve for $n_{\mathrm{e}}=1.0 \times 10^{16} \mathrm{~cm}^{-3}$.

Figure 4. Contours of the ratio of ionizations per photon $S_{\mathrm{Li} \rightarrow \mathrm{He}} / \epsilon_{\mathrm{Li}}$ for carbon (top) and oxygen (bottom) for the transition $3 \mathrm{p}^{2} \mathrm{p}^{0} \rightarrow 3 \mathrm{~s}^{2} \mathrm{~S}$ to the corresponding quantity of hydrogen $\mathrm{H} \alpha$.

The line average electron density, measured by interferometry, is in the range $5 \times 10^{13}$ $5 \times 10^{14} \mathrm{~cm}^{-3}$, the electron temperature is $\leqslant 200 \mathrm{eV}$ and the particle confinement time is 10-60 $\mu \mathrm{s}$. According to figures 1 and 2 the method presented in section 2 can be applied, 
since $1 /\left(n_{\mathrm{e}} S_{\mathrm{He} \rightarrow \mathrm{H}}\right) \approx 1 \mathrm{~ms}$ and $1 /\left(n_{\mathrm{e}} \alpha_{\mathrm{He} \rightarrow \mathrm{Lj}}\right) \approx 5 \mathrm{~ms}$ under these conditions. Thus, the loss of He-like oxygen is given by $\tau_{p}$, and the ratio of the fractional abundances between He-like and Li-like ions will be reduced to less than $1 / 100$, when compared with the result that would follow from a balance between ionization and recombination (see equations (3) and (4)).
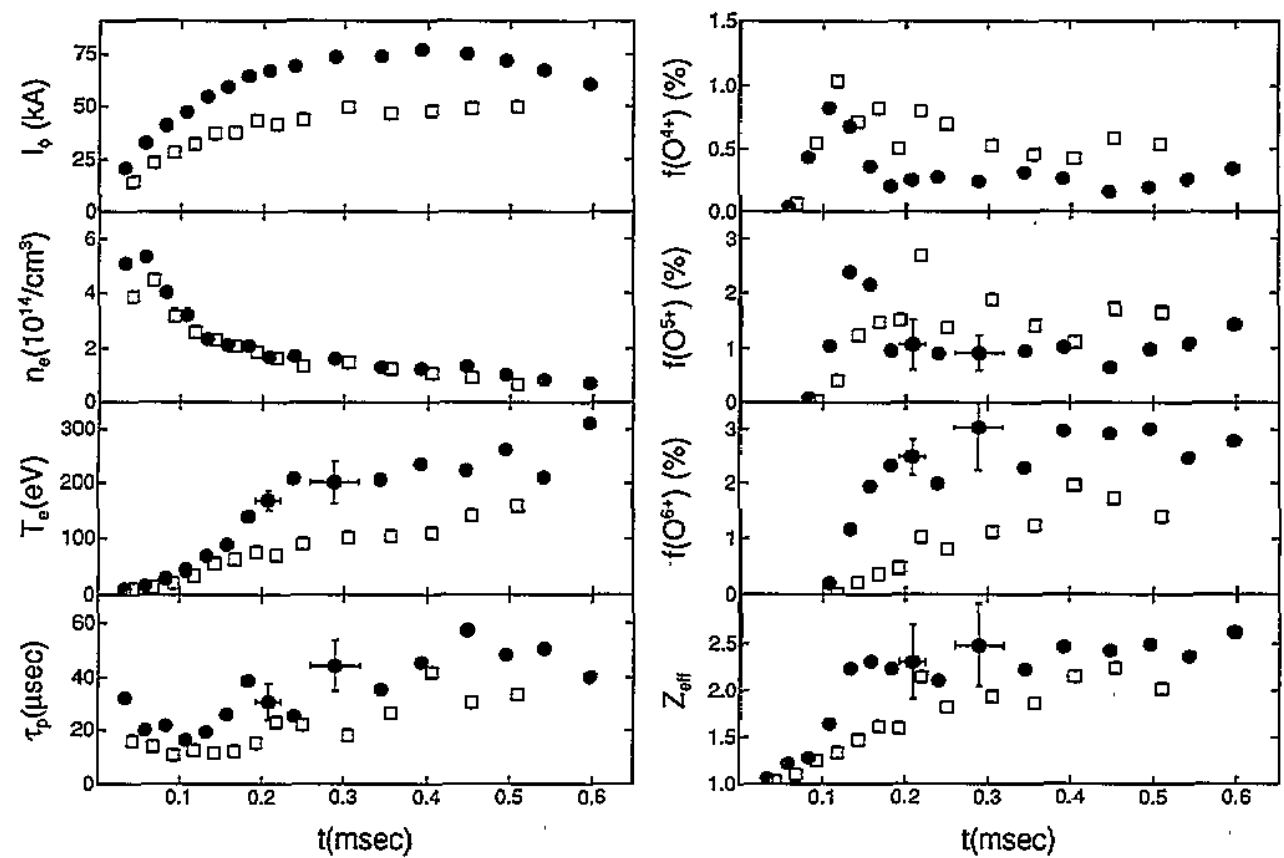

Figure 5. Results for Extrap-T1 RFP discharges at $50 \mathrm{kA}(\square)$ and at $80 \mathrm{kA}(\bullet)$ in deuterium. Each data point in the figures represents the average result from five discharges during the current rise phase (for times before $0.2 \mathrm{~ms}$ ), and from ten discharges for times after $0.2 \mathrm{~ms}$. Spectra are taken during $35 \mu \mathrm{s}$. A few representative error bars are given to illustrate the averaged time intervals and the shot-to-shot variation. Further error bars are omitted for clarity. Left from top to bottom: toroidal plasma current $I_{\phi}$; line average electron density $n_{\mathrm{c}}$; line ayerage electron temperature $T_{\mathrm{c}}$ from VUV line intensity ratios; particle confinement time $\tau_{\mathrm{p}}$. Right from top to bottom: fraction of oxygen jons $\mathrm{O}^{4+}$ and $\mathrm{O}^{5+}$ obtained from VUV radiances using a zerodimensional collisional radiative model; fraction of $\mathrm{O}^{6+}$ obtained from the method described in this paper, using the radiance of $3 \mathrm{p}^{2} \mathrm{P}^{0} \rightarrow 2 \mathrm{~s}^{2} \mathrm{~S}$; effective ion charge $Z_{\text {eff }}$ obtained by summing over individual contributions from all measured ion species of carbon, nitrogen, oxygen and chlorine.

In figure 5 we present toroidal plasma current, $\lambda_{\phi}$, line average electron density, $\left\langle n_{\mathrm{e}}\right\rangle$, line average electron temperature, $\left\langle T_{e}\right\rangle$, and particle confinement time, $\tau_{p}$, together with the results for the oxygen ionization balance as obtained from two series at 50 and $80 \mathrm{kA}$ in deuterium. The electron density is approximately equal for the two series, while the electron temperature reaches $100 \mathrm{eV}$ for the $50 \mathrm{kA}$ series, and $200 \mathrm{eV}$ for the $80 \mathrm{kA}$ series. For the experiments, we use a VUV spectrometer (Fonck et al 1982, Brzozowski et al 1991) which has been absolutely calibrated using the branching ratio technique (Klose and Wiese 1989). One of the branching ratios that has been used is the $\mathrm{O}^{5+} 3 \mathrm{p}^{2} \mathrm{P}^{0} \rightarrow 2 \mathrm{~s}^{2} \mathrm{~S}$ to $\mathrm{O}^{5+}$ $3 \mathrm{p}^{2} \mathrm{P}^{\circ} \rightarrow 3 \mathrm{~s}^{2} \mathrm{~S}$ line ratio. VUV spectra are taken during $35 \mu \mathrm{s}$ and the gate time is varied from shot to shot. 
The line average electron temperature is measured using the intensity ratio of $\mathrm{O}^{5+}$ $3 \mathrm{p}^{2} \mathrm{p}^{\circ} \rightarrow 2 \mathrm{~s}^{2} \mathrm{~S}$ to $\mathrm{O}^{5+2} 2 \mathrm{p}^{2} \mathrm{P}^{\circ} \rightarrow 2 \mathrm{~s}^{2} \mathrm{~S}$. This electron temperature represents the plasma conditions under which $\mathrm{O}^{5+}$ is ionized, which is the relevant temperature for the estimate of $\mathrm{O}^{6+}$ abundances. It is interesting to note that the measured temperatures exceed the temperature of maximum fractional abundance for $\mathrm{O}^{5+}$ that would be obtained if the ionization balance between $\mathrm{O}^{5+}$ and $\mathrm{O}^{6+}$ were to be given by ionization and recombination. Due to the transient ionization, this equilibrium charge state distribution is not reached. This fact is exploited by our measurement. In the initial phase of the discharge, when $\mathrm{O}^{5+}$ is not observed, we use the line ratios of $\mathrm{O}^{4+}$ and $\mathrm{O}^{3+}$ for the measurement of the electron temperature.

The line average densities of oxygen ionization stages up to $\mathrm{O}^{5+}$ were derived using a zero-dimensional collisional-radiative model. The atomic data for this study have been collected by Lang and Summers. Metastable and ground-state densities are measured seperately for $\mathrm{O}^{2+}, \mathrm{O}^{3+}$ and $\mathrm{O}^{4+}$, and these ion populations are then added to obtain the total density. In the case of $\mathrm{O}^{4+}$, reported in figure 5 , we used $\mathrm{O}^{4+} .629 .73 \AA$ and $\mathrm{O}^{4+}$ $758.68-762.00 \AA$ to measure $2 s^{21} \mathrm{~S}$ and $2 \mathrm{~s} 2 \mathrm{p}{ }^{3} \mathrm{P}^{\circ}$.

Details of the measurement of the deuterium influx, $\Gamma_{D}$, are given in appendix $A$. Since the density is, in fact, varying on a time scale comparable with $\tau_{p}$, we modify equation (5) in order to obtain $\tau_{\mathrm{p}}$ according to

$$
\tau_{\mathrm{p}}=\left\langle n_{\mathrm{d}}\right\rangle /\left(\frac{A}{\gamma V} \Gamma_{\mathrm{D}}-\frac{\mathrm{d}\left\langle n_{\mathrm{d}}\right\rangle}{\mathrm{d} t}\right)
$$

where $\gamma$ is a shape factor obtained from the density profile, which is assumed parabolic, and $\left\langle n_{\mathrm{d}}\right\rangle$ is given by equation (11). Since it turns out, that $\mathrm{O}^{6+}$ gives a major contribution to the plasma dilution, the calculation has to be repeated several times, until self-consistent results are obtained. Starting with a given deuterium influx and a plasma dilution based upon ions up to $\mathrm{O}^{5+}$, the particle confinement time is used to calculate the fraction of $\mathrm{O}^{6+}$. When this ion density is included, the result for the deuteron density decreases, therefore the resulting $\tau_{\mathrm{p}}$ is reduced, the corresponding calculated density of $\mathrm{O}^{6+}$ is reduced and vice versa in the next iteration step.

In figure 5 we can see the following trends for the oxygen ionization balance. For the $80 \mathrm{kA}$ series, $\mathrm{O}^{4+}$ reaches its maximum fraction at around $0.12 \mathrm{~ms}$, and the maximum of $\mathrm{O}^{5+}$ is seen around $0.15 \mathrm{~ms}$ into the discharge. Then, both directly measured ionization stages return to a lower level, which is approximately constant throughout the discharge. The calculated fraction of $\mathrm{O}^{6+}$ rises to an approximately constant level during the first $0.2 \mathrm{~ms}$. For the $50 \mathrm{kA}$ series, a different result is obtained due to the lower electron temperature and particle confinement time. The fraction of $\mathrm{O}^{4+}$ and of $\mathrm{O}^{5+}$ remains almost constant throughout the discharge. The calculated result for $\mathrm{O}^{6+}$ indicates a slow rise, to values around $1 \%$. The ionization balance thus is shifted towards a lower average ion charge in the $50 \mathrm{kA}$ series compared with the $80 \mathrm{kA}$ series. This is consistently observed for the ratio between the directly measured fraction of $\mathrm{O}^{5+}$ and $\mathrm{O}^{4+}$ and for the ratio between the calculated fraction of $\mathrm{O}^{6+}$ and the directly measured fraction of $\mathrm{O}^{5+}$.

Other plasma species such as carbon, nitrogen and chlorine have concentrations typically less than $10 \%$ of the oxygen concentration. Since all dominant ion fractions, $f_{i}$, are measured for each species $i$ with charge $Z_{i}$, we can explicitly calculate the effective ion charge, $Z_{\text {eff }}$, the line average deuteron density, $\left\langle n_{\mathrm{d}}\right\rangle$, and the total particle density, $\langle n\rangle$, as

$$
Z_{\text {eff }}=1+\sum_{i} f_{i} Z_{i}\left(Z_{i}-1\right)
$$




$$
\begin{aligned}
& \left\langle n_{\mathrm{d}}\right\rangle=\left\langle n_{\mathrm{e}}\right\rangle-\sum_{i} f_{i}\left\langle n_{\mathrm{e}}\right\rangle Z_{i} \\
& \langle n\rangle=\left\langle n_{\mathrm{e}}\right\rangle+\left\langle n_{\mathrm{d}}\right\rangle+\sum_{i} f_{i}\left\langle n_{\mathrm{e}}\right\rangle .
\end{aligned}
$$

The result for $Z_{\text {eff }}$ is also shown in figure 5 . An alternative method to obtain $Z_{\text {eff }}$ by a measurement of the absolute level of the continuum intensity has not been possible, since no sufficiently wide wavelength region free of spectral lines could be found. On the other hand, such a measurement on its own would not be sufficient, since neither $\left\langle n_{\mathrm{d}}\right\rangle$ nor $\langle n\rangle$ can be obtained in this way, without further knowledge of the plasma composition. From $Z_{\text {eff }}$ and with $T_{\mathrm{e}}$ in $\mathrm{eV}$, we can then calculate the Spitzer resistivity $\eta_{\mathrm{S}}$ and resistance $R_{\mathrm{S}}$

$$
\begin{aligned}
& \eta_{S}=3.04 \times 10^{-5} \frac{\ln \Lambda\left(n_{\mathrm{e}}, T_{\mathrm{e}}, Z_{\text {eff }}\right) Z_{\text {eff }}}{\gamma_{E}\left(Z_{\text {eff }}\right) T_{\mathrm{e}}^{3 / 2}} \\
& R_{\mathrm{S}}=\frac{2 R_{0}}{a^{2}} f(\Theta) \eta_{\mathrm{S}}
\end{aligned}
$$

where $R_{0}$ is the major radius, $a$ is the minor radius, and the factor $f(\Theta)$ considers the helical structure of the parallel current in an RFP (Sprott 1988). The coefficients $\ln \Lambda\left(n_{\mathrm{e}}, T_{\mathrm{e}}, Z_{\mathrm{eff}}\right)$ and $\gamma_{E}\left(Z_{\text {eff }}\right)$ are given by Spitzer (1962). For both the series of discharges presented here, $R_{S}$ accounts for $50-70 \%$ of the total plasma resistance for times before $0.1 \mathrm{~ms}$, and for $20-40 \%$ for times after $0.1 \mathrm{~ms}$. The behaviour of the non-Spitzer loop voltage, $I_{\phi}\left(R-R_{S}\right)$, reflects the activity of the so-called dynamo process that sustains the magnetic fieId configuration.

For the measurement of the plasma composition, specifically for a calculation of $Z_{\text {eff }}$, $n_{\mathrm{d}}$ and $n$, it is necessary to measure the density of all ionization stages up to and including $\mathrm{O}^{6+}$ under the transient ionization conditions in Extrap-T1. With these densities, Spitzer plasma resistivity, an improved result for the particle confinement time, and an estimate of the total plasma pressure can be obtained. Our method makes these results available to us with visible and VUV spectroscopy alone.

\section{Acknowledgments}

We are indebted to Professor Hugh P Summers and his co-workers for supplying part of their large and comprehensive collection of atomic data. This work has been supported by the European Communities under an association contract between EURATOM and the Swedish Natural Science Research Council.

\section{Appendix A. Measurement of particle influx}

The influx of deuterium is obtained from the intensity of $\mathrm{D} \alpha$ based on assumptions on the radial profiles of $T_{e}$ and $n_{\mathrm{e}}$ necessary to obtain the radiance per unit influx. In this model, the radial profile of the electron density is assumed to be parabolic, i.e. $n_{\mathrm{e}}(r)=n_{\mathrm{e}}(0)\left(1-(r / a)^{2}\right)^{\alpha_{n}}$ with $\alpha_{n}=1.0$, and the electron temperature is assumed almost flat, i.e. $T_{\mathrm{e}}(r)=T_{\mathrm{e}}(0)\left(1-(r / a)^{2}\right)^{\alpha_{T}}$, with $\alpha_{T}=0.1$. Then, for a given influx $\Gamma_{\mathrm{D}}$ of 
deuterium atoms with velocity $v_{\mathrm{D}}$, the radial profile of the deuterium atom density $N_{n}(r)$ in level $n$ can be obtained solving

$$
\begin{aligned}
& -\frac{1}{r} \frac{\partial}{\partial r}\left(r \Gamma_{\mathrm{D}}\right)-S(r) n_{\mathrm{e}}(r) N_{1}(r)=0 \\
& \quad \Rightarrow N_{1}(r)=N_{\mathrm{L}}(a)\left(\frac{a}{r}\right) \exp \left(-\int_{r}^{a} \frac{n_{\mathrm{e}}(r) S(r)}{v_{\mathrm{D}}} \mathrm{d} r\right)
\end{aligned}
$$

$\frac{N_{n}(r)}{N_{1}(r)}=n^{2} \exp \left(-\frac{E_{n}-E_{1}}{T_{\mathrm{e}}(r)}\right) r_{1}(n)$.

Here, $S$ and $r_{\mathrm{I}}$ are the quantities taken from Johnson and Hinnov (1973), evaluated for the local electron temperature and density. From the profile of $N_{3}(r)$, we obtain the radiance of $\mathrm{D} \alpha$ per unit influx by integration along the line-of-sight. This quantity is found to be mainly dependent on $\left\langle n_{\mathrm{e}}\right\rangle$ and weakly dependent on $\left\langle T_{\mathrm{e}}\right\rangle$ over the operational regime of Extrap-T1. Since both $\left\langle n_{\mathrm{e}}\right\rangle$ and $\left\langle T_{\mathrm{e}}\right\rangle$ are measured, we can calculate the deuterium influx from the observed radiance of $\mathrm{D} \alpha$ using this quantity. Choosing different profile parameters for density and temperature within reasonable limits, i.e. $0.5 \leqslant \alpha_{n} \leqslant 2.0$ for the density and $0.0 \leqslant \alpha_{T} \leqslant 0.5$ for the temperature, the coefficient changes as much as $20 \%$. The choice of $v_{D}$ does not affect the result, as long as the assumption behind the solution to equation (15), that the flux of deuterium vanishes for $r=0$, remains valid. For typical parameters in Extrap-T1, this assumption holds for velocities up to $3 \times 10^{4} \mathrm{~m} \mathrm{~s}^{-1}$, corresponding to a kinetic energy of $10 \mathrm{eV}$.

\section{References}

Arnaud M and Rothenflug R 1985 Astron. Astrophys. Suppl. Series 60425

Behringer K, Summers H P, Denne B, Forrest M and Stamp M 1989 Plasma Phys. Control. Fusion 312059

Brunsell P, Drake J R, Mazur S and Nordlund P 1991 Phys. Scr. 44358

Bodin H A B 1990 Nucl. Fus. 301717

Brzozowski J H, Källne E and Zastrow K-D 1991 Phys. Scr. 43283

Carolan P G and Piotrowicz V A 1983 Plasma Phys. 251065

Cochrane D M and McWhirter R W P 1983 Phys. Scr. 2825

Fonck R J, Ramsey A T and Yelle R V 1982 Appl. Opt. 212115

Fussmann G, Field A R, Kallenbach A, Krieger K, Steuer K-H and the ASDEX-Team 1991 Plasma Phys. Control. Fusion 331617

Johnson L C and Hinnov E $1973 \mathrm{~J}$. Quant. Spectrosc, Radiat. Trans. 13333

Klose J Z and Wiese W L 1989 J. Quant. Spectrosc. Radiat. Trans. 42337

Lang $J$ and Summers $\mathbf{H} P$ private communication

Spitzer L Jr 1962 Physics of Fully Ionized Gases 2nd edn (New York: Wiley Interscience) p 136ff

Sprott J C 1988 Phys. Fluids 312266

Summers H P 1974 Mon. Not. R. Astron. Soc. 169663

Zhang H L, Sampson D H and Fontes C J 1990 At. Data Nucl. Data Tables 4431 